\title{
客UTS
}

\section{UNDERSTANDING PUBLIC EXPECTATIONS OF HEALTHCARE QUALITY AND SAFETY REGULATION IN AUSTRALIA}

POLICY BRIEF: AUTUMN 2018

\section{Policy Implications}

1. The safety of health care remains an important area of healthcare regulation: 1 in 10 patients are likely to sustain harm in association with a hospital admission and 1 in 50 a death or major disability because of the health system rather than their underlying disease or injury;

2. At present, there are differences between the views of the community and existing regulatory frameworks;

3. The general public expect a graduated approach to stakeholder responsibility, monitoring and regulatory responses to failures in the quality and safety of healthcare;

4. Reliance on decentralised accreditation-centric quality improvement mechanisms is not sufficient. The community expects more centralised oversight, including strict norm-referenced monitoring and performance testing - including in-person 'spot inspections', rather than reliance on self-monitoring and reporting.

\section{The regulation of healthcare services has a range of goals.}

Improving the safety and quality of healthcare is one of them. Regulatory efforts to support healthcare safety in particular should be responsive to concerns, values and attitudes of the community - who are co-creators and arbiters of normative standards, of what constitutes acceptable political and social practices and in whose name regulatory efforts are enacted and enforced by government and other stakeholders.

To achieve these aims good regulation must be practical, cohesive and empirically-based. However, there is a lack of good quality evidence about what members of the Australian community believe and expect in relation to the regulation of healthcare safety.

- While patient and consumer consultation has been on the agenda for many years, to date there has been a lack of real information about community perspectives in the discussion.

- There are important areas of disagreement between the way we regulate healthcare safety and the community's concerns, values and attitudes.

\section{There is a divergence between the way} we regulate healthcare safety and the community's concerns, values and attitudes. 


\section{Background}

Understanding the general public's view of healthcare quality and safety regulation first requires an understanding of the regulatory framework. The Australian approach to regulating healthcare quality and safety is 'multidimensional'.' It utilises an 'institutional constellation'1 of government, professions, market and civil society regulatory actors, each operating at the health service entity, State and Territory, national, intergovernmental and supranational levels with a mix of formal and informal regulatory powers to 'influenc[e] the flow of events' 2 towards safer healthcare.

Because there is a lack of good quality evidence about what members of the Australian community believe and expect in relation to the regulation of healthcare safety, we wanted to answer two questions:

1. Who do members of the general public think should bear responsibility for the safety and quality of healthcare in Australia?

2. What do members of the general public think are appropriate ways to monitor and respond to healthcare safety issues?
To elicit the Australian public's voice on issues related to the governance of health care quality and safety, we developed a survey tool that reflected these core elements of Australian approach to regulating health care. ${ }^{3}$ We asked approximately 1000 NSW residents 'who should bear the responsibility for safety and quality of healthcare in NSW?' (while also asking who should bear the responsibility for food prepared outside of the home?)

Those who responded to the survey ranked health practitioners as those who should bear the greatest responsibility for the quality and safety of health services. This group was closely followed by a cluster of governmental actors, namely, the (NSW) Minister for Health, the State Government and then the Federal Government.

\section{Who do members of the general public think should bear responsibility for the safety and quality of healthcare in Australia?}

Table 1: 'Responsibility Scores' (mean score out of possible maximum of 5) for regulatory actors in the health care and food services sectors in NSW.

\section{REGULATORY ACTOR}

Individual patients|Individual consumers
HEALTH CARE

3.44

3.97

3.46

4.06

work with personnel who prepare food

Managers of health services|Managers of food-related businesses

3.71

4.27

The Minister for Health in your State of Territory|The NSW

Minister responsible for food safety regulation

The NSW government

FOOD SERVICES

2.89

The Federal (Commonwealth) government 
Following this cluster were managers of health services, followed finally by those who support the work of health practitioners, and individual patients.

We performed further statistical analysis on these results to understand how respondents thought about responsibility attribution in more detail. Interestingly, two different models emerged. One group viewed responsibility for healthcare quality and safety as very much a shared and homogenous enterprise where different stakeholders were more or less responsible than others, but that all stakeholders bear responsibility in a shared way. The other group identified what we call the 'patient-practitioner-support triad' as bearing the most responsibility.

This 'triad' was made-up of those who are involved in the day-to-day clinical encounter - patients themselves, health practitioners and those who directly support the work of health practitioners. This second group highlighted the role of the 'triad' in contrast to those who are more distant from the bedside, like managers of health services or the minister for health who they felt held less responsibility for the quality and safety of healthcare.

Who held these two views of responsibility for healthcare safety? Those who were older and who had more exposure to the health care system were more likely to emphasise responsibility across all stakeholders first, and then would highlight the role of the 'triad' rather than those more distant stakeholders. Those who were younger gave less emphasis across all actors but were then more likely to emphasise the role of those distant actors (e.g. governmental actors). Interestingly, those who hold higher satisfaction with the health system also emphasise responsibility across all actors.

\section{What do members of the general public think are appropriate ways to monitor and respond to healthcare quality and safety issues?}

Approximately $70 \%$ of respondents also indicated that they agreed or totally agreed that the regulator could rely upon the complaints of members of the public or consumer groups to monitor health care quality; yet, only $53 \%$ of respondents agreed or totally agreed that the information provided by health care institutions themselves could be relied upon by the regulator.

Respondents were also asked about mechanisms the regulator should use where a hospital has "fallen below community expectations of quality of care ...and patients are harmed". Responses (Figure 2) indicated overwhelming support for the "regulator" providing recommendations for improvement to the hospital, with 89\% agreeing or totally agreeing with that mechanism's use. This was followed closely by the regulator visiting the hospital to "doublecheck" the hospital and its services (87\%). In a relatively regular pattern of descending rank order, respondents agreed or totally agreed that the regulator should publish the failure to provide adequate quality of care (72\%), issue the hospital with a fine (67\%), inform the media of the failure (61\%) and finally to temporarily take over the management of the hospital (55\%). More respondents disagreed or totally disagreed with the option of closing the hospital (39\%) than had agreed or totally agreed with it (23\%). 


\section{To monitor the quality of healthcare, the regulator could best:}

$13 \%$ $86 \%$

$12 \%$

$18 \%$

$79 \%$

$7 \% \quad 21 \%$

$72 \%$

$7 \% \quad 24 \%$

$69 \%$

$8 \% \quad 22 \%$

$69 \%$

$\begin{array}{lll}18 \% & 27 \% & 55 \%\end{array}$

$21 \% \quad 39 \% \quad 40 \%$

20

Totally disagree + Disagree

Neither disagree nor agree
Test each healthcare institution's performance against very strict standards that every institution must reach.

Make unannounced 'spot inspections' of care institutions.

Personally visit and inspect all care institutions.

Rely on the complaints of health care providers.

Rely on the complaints of members of the public.

Rely on the complaints of patient or consumer groups.

Rely on information provided by the healthcare institutions themselves.

Search the internet for complaints about healthcare institutions.

Figure 1: The best ways the regulator could monitor the Quality of Healthcare .

\section{What do you think the regulator should do where a hospital has fallwn below community expectations of quality care for their patients and patients are harmed?}

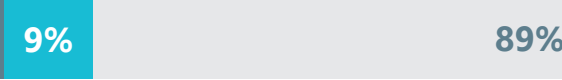

$11 \%$

$5 \% \quad 23 \%$

$72 \%$

$10 \% \quad 23 \%$

$67 \%$

$10 \% \quad 30 \%$

$61 \%$

\section{$10 \%$}

$36 \%$

$55 \%$

$19 \%$

$39 \%$

$42 \%$

$39 \%$

$39 \%$

$23 \%$
Provide recommendations for inprovements to the hospital.

Visit the hospital to 'double check' the hospital and its services.

Publish the failure to provide adequate quality of care on the regulator's own webdite.

Issue the hospital with a fine.

Inform the media of the failure to provide adequate quality of care.

Temporarely take over the management of the hospital.

Advise patients to go to another hospital.

Close the hospital.

Figure 2: Expected Response to a Failure in Healthcare Quality and Safety. 


\section{The Implications}

These results reveal the public's relative ranking of stakeholder responsibility (Table 1), their expectations regarding monitoring activities (Figure 1) and of responses to a failure in healthcare quality and safety (Figure 2).

In relation to stakeholder responsibility, respondents indicated that individual health care practitioners, specifically those who treat individual patients, should bear the most significant responsibility for the quality and safety of health care. This expression of the public's expectations is an opportunity to clarify ongoing discourse about health practitioner agency, control and choice in relation to the quality and safety of health care. This is an oftentimes tense exchange, particularly in relation to iatrogenic harm, where health practitioners and scholars point to the 'systemic'4 influences on safety and quality in healthcare - where upstream factors outside of an individual practitioner's direct control can be a decisive influence on whether a healthcare encounter results in safety or harm for a patient. ${ }^{5}$

In relation to monitoring and responding to the safety and quality of healthcare, the results show that respondents expect a highly engaged and proactive approach to monitoring health care quality performance as well as in response to healthcare-related harm. Notable is the very strong support for personal "double-checking" and "spot inspections" of health services in the manner of more invasive auditing "against very strict standards" which each institution must reach. These monitoring practices rely on a more centralised regulatory actor or power, intervention through performance testing against normative standards, and in-person "spot inspections" alongside scheduled inspections. This interest in a more activist, personal and involved inspection and audit process against "strict" normative standards we believe indicates support for a more "mastery"-focused approach; rather than self-reporting against minimum standards and a commitment to quality improvement, this mastery approach would tend towards testing the achievement of safe and high quality health services. This approach differs from the approach taken in most contemporary approaches to hospital accreditation, which rely largely on self- produced/reported data on the establishment and operation of quality improvement processes, rather than achievement against normative standards of a "very strict" or high-quality nature. Other important divergences exist in relation to both practices of enforcement. These results demonstrated a marked decrease in support for reliance on information provided by health care institutions themselves. Thus, there is a preference towards centrally collected, norm-referenced forms of monitoring. These public expectations differ materially from current practices, particularly the more flexible continuous quality improvement methodology that dominates the accreditation-centric quality and safety governance model.

This is not to say that the public are not supportive of process improvement, and a focus on process. Rather, there is almost complete (88\%) support for the provision of recommendations to improve hospital services when a patient has been harmed. However, this is held in tension with the more invasive and 'inspection-oriented' practice of visiting the hospital (by the regulator) to 'doublecheck' its services and support that seems to resist the decentralising nature of our current system of monitoring and quality improvement.

Some further areas of work need to be done to establish more clearly exactly what the expectations of the public are. For example, the public holds government and governmental actors largely responsible for the quality and safety of healthcare, with individual health practitioners, those entrusted with a duty to ensure our care, similarly positioned. We interpret this centrality of government and governmental actors in the mix of those responsible as countering any tendency towards a decentralised or devolved, "market-designing" or other "backstop" role for the State, the 'regulator' or the medical profession. Rather, the public understand those actors to bear the greatest responsibility for the quality and safety of care and when viewed alongside their expectations for a highly active, inspection-oriented and interventionist form of monitoring and healthcare harm response, we expect this points towards a much more active form of regulatory monitoring, rather than reliance upon individual institutions with devolved and decentralised regulatory power through accreditation and accreditation-like processes. 


\section{Policy Practitioners, Regulators and Decision Makers Should...}

All regulation should be practical, empirically based and responsive to community concerns. To achieve this, policy makers, regulators and decision makers should ensure that at least the following three points are integrated into future regulation reform or law making in the area of patient safety:

1. Regulatory frameworks and mechanisms should be responsive to the views of the community.

2. Monitoring practices should include more robust, independent and norm-referenced.

3. Responses to failures in healthcare quality and safety where a patient is harmed need to support change, however, the public are strongly supportive of much more interventionist responses, including confirmatory 'double-checking' of the safety of a healthcare by use of unannounced 'spot checks' that check the delivery of health services against very strict standards.

\section{Reference List:}

1. Healy J. Improving Health Care Safety and Quality: Reluctant Regulators. Ashgate Publishing, Ltd.; 2013. 349 p.

2. Parker C, Scott C, Lacey N, Braithwaite J. Introduction. In: Parker C, Scott C, Lacey N, Braithwaite J, editors. Regulating Law. Oxford University Press; 2004. p. 1-12.

3. Carter DJ, Brown J, Saunders C. The Patient's Voice: Australian Health Care Quality and Safety Regulation from the Perspective of the Public. Journal of Law \& Medicine. 2018;25(2):408-28.

4. Corbett A, Travaglia J, Braithwaite J. The role of individual diligence in improving safety. Journal of Health Organization and Management. 2011;25(3):247-260.

5. Waring J, Allen D, Braithwaite J, Sandall J. Healthcare quality and safety: a review of policy, practice and research. Sociol Health IIIn. 2016 Feb 1;38(2):198-215.

FOR MORE INFORMATION SEE OUR RECENT PUBLICATION: The Patient's Voice: Australian Health Care Quality and Safety Regulation from the Perspective of the Public.

Carter DJ, Brown J, Saunders C.

Journal of Law \& Medicine. 2018;25(2):408-28.

\section{About the authors}

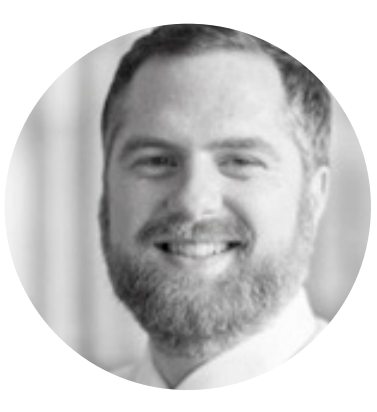

David J Carter is a Lecturer in Law and member of the Law | Health | Justice Research Centre in the Faculty of Law, University of Technology Sydney.

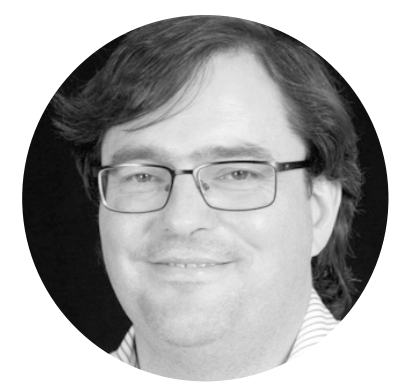

James Brown is Professor of Official Statistics, in the School of Mathematical and Physical Sciences, Faculty of Science, University of Technology Sydney and the Australian research Council Centre of Excellence for Mathematical and Statistical Frontiers.

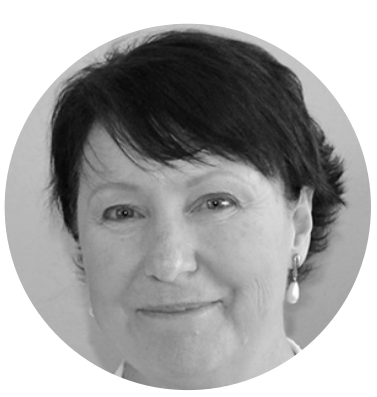

Carla Saunders is a Lecturer in Health Services Management and member of the Centre for Health Services Management at the Faculty of Health, University of Technology Sydney. 